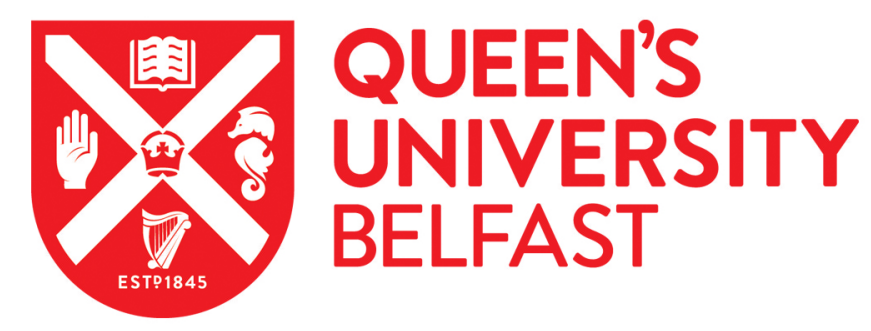

\title{
The use of process simulation methods in support of organisational learning in availability contracting
}

McEwan, W., \& Butterfield, J. (2011). The use of process simulation methods in support of organisational learning in availability contracting. Journal of Aerospace Operations, 1(1-2), 41-53. https://doi.org/10.3233/AOP2011-0003

Published in:

Journal of Aerospace Operations

Document Version:

Early version, also known as pre-print

Queen's University Belfast - Research Portal:

Link to publication record in Queen's University Belfast Research Portal

Publisher rights

C 2012 - IOS Press and the authors. All rights reserved

\section{General rights}

Copyright for the publications made accessible via the Queen's University Belfast Research Portal is retained by the author(s) and / or other copyright owners and it is a condition of accessing these publications that users recognise and abide by the legal requirements associated with these rights.

Take down policy

The Research Portal is Queen's institutional repository that provides access to Queen's research output. Every effort has been made to ensure that content in the Research Portal does not infringe any person's rights, or applicable UK laws. If you discover content in the Research Portal that you believe breaches copyright or violates any law, please contact openaccess@qub.ac.uk. 


\title{
The use of process simulation methods in support of organisational learning in availability contracting
}

\author{
W. McEwan and J. Butterfield* \\ Queen's University Belfast, Northern Ireland
}

\begin{abstract}
Traditional business models in the aerospace industry are based on a conventional supplier to customer relationship based on the design, manufacture and subsequent delivery of the physical product. Service provision, from the manufacturer's perspective, is typically limited to the supply of procedural documentation and the provision of spare parts to the end user as the product passes through the latter stages of its intended lifecycle. Challenging economic and political conditions have resulted in end users re-structuring their core business activities, particularly in the defence sector. This has resulted in the need for original equipment manufacturers (OEMs) to integrate and manage support service activities in partnership with the customer to deliver platform availability. This improves the probability of commercial sustainability for the OEM through shared operational risks while reducing the cost of platform ownership for the customer. The need for OEMs to evolve their design, manufacture and supply strategies by focusing on customer requirements has revealed a need for reconstruction of traditional internal behaviours and design methodologies. Application of organisational learning is now a well recognised principle for innovative companies to achieve long term growth and sustained technical development, and hence, greater market command. It focuses on the process by which the organisation's knowledge and value base changes, leading to improved problem solving ability and capacity for action. From the perspective of availability contracting, knowledge and the processes by which it is generated, used and retained, become primary assets within the learning organisation. This paper will introduce the application of digital methods to asset management by demonstrating how the process of learning can benefit from a digital approach, how product and process design can be integrated within a virtual framework and finally how the approach can be applied in a service context.
\end{abstract}

Keywords: Organisational Learning, Availability Contracting, Through Life Management, Digital Manufacturing

\section{Introduction}

Traditional aircraft manufacturing practice has supported a product centered philosophy where platform delivery represented the end of the primary relationship between the OEM and the customer, excepting the provision of spare parts and repair services. Increasing operational pressures in the form of cost reductions, particularly from the perspective of military customers such as the UK MOD Smart Acquisition Reforms [1], and operational pressures arising from challenging market conditions, are driving an increasing

\footnotetext{
${ }^{*}$ Corresponding author: J. Butterfield, Lecturer, School of Mech. \& Aero. Eng., QUB, Ashby Building, Stranmillis Rd., Belfast, BT9 5 AH, Northern Ireland; E-mail: j.butterfield@qub.ac.uk.
} 
need for the provision of customer solutions in product offerings across a broader section of the product lifecycle. Concepts of through life management (TLM) or through life Support (TLS) espouse this concept and service based contract arrangements are now recognized and encouraged at a government level in the UK through recent programmes such as the Aerospace Innovation and Growth Team (AeIGT) and Support Service Solutions: Strategy and Transition (S4T). Both programmes have identified and investigated the need for a more detailed understanding of the strategic shift towards TLM across the aerospace industry and what changes are required with regard to customer support and Maintenance, Repair \& Overhaul (MRO) activities [2].

TLM could be viewed as a more holistic approach to the meaning of the word "Product," where, in addition to the purchase of the actual platform, training, maintenance, upgrade and disposal plans as provided by the OEM, are also considered as key aspects of ownership. This model is comparable to the concept of lean consumption which focuses on a product solution driven primarily by the customer requirement [3]. The major drivers for TLM have been identified as, customer demand, increased revenues and increased competitiveness [4-6]. Customer demand is viewed slightly differently according to whether the customer is military or civilian. Civil airlines are demanding greater reliability and a reduction in spares and necessary maintenance with a view to longer intervals between MRO events. This particular objective is the one reason for the increased application of advanced composites in civil airframes [7, 8], and thus we can assume that MRO based drivers in civil aerospace will only increase in the future. Military requirements traditionally focused on performance requirements and the continuing reduction in the size of some air forces, coupled with well documented government driven intentions to reduce defence expenditures worldwide, has led to a re-definition of air force roles. Rapid deployment, simplified logistics and minimal support are now key to their performance [9] and operational availability is their primary requirement.

The terms, availability, TLM, TLS and PLM can all be viewed as sharing the same objectives with respect to aircraft design. It is worth noting here that concepts of whole life system design not only produce products which meet the customers' demands, but provide the opportunity for improving capability by creating an intelligent design which goes beyond the primary requirements. Where maintenance has been viewed merely as a necessary function for the mitigation of financial loss, in the case of the airline, or loss of operational capability, in the case of the military, investing in a TLS strategy can actually be viewed as an investment by allowing the operator to focus on their value adding activities [10].

From the afore mentioned requirements it can be seen that from a design perspective, there is an increased need for maintenance and repair considerations to be better integrated within engineering design in order to optimise the products and processes sold to a customer on an availability contracting basis. Altering the cultural and technical habits of complex engineering teams to accommodate these new design drivers, presents a significant alteration of organisational behaviours and working practices. This presents a serious concern to manufacturing companies as it presents a significant challenge in terms of transitioning to platform availability from product supply. Organisational learning presents a well recognized concept for the mobilization of intellectual activity within companies to achieve this aim. An excellent definition is "the process by which the organisation's knowledge and value base changes, leading to improved problem solving ability and capacity for action." [11] As a concept, it can not only assist in the expedient transformation of design teams to accommodate shifts in requirements, and hence make it to market quickly, but also provides a means of instilling dynamism and innovation within the company. Adaptation is now recognized as a key difference between companies that flourish and companies that receed [12], and a learning organisation should be adaptive. "Adaptation or reaction to environmental pressures will lead an organisation to change and perhaps to learn, and learning faster than others will 
increase an organisation's chances to survive. Innovation is a necessity and not a choice, and innovation may be perceived as a learning process" [13]. Further to this, there is a strong argument to make that teamwork is the key to innovation [14]. Aerospace design teams are typified by large numbers of highly skilled but often disparate diciplines, each of which has different vision or interpretation of what the intended product should look like. This is a direct result of the ever increasing complexity of aerospace systems and the resultant need for technical specialisation from engineers. Ever larger and more specialized staff requirements results in larger organisations with proportionally complex organisational structures. As a result, issues concerning the management of the myriad departments of design and development, and a shared sense of objective, grows also. Concurrent engineering and systems engineering techniques have gone some way to improving the intercommunication and shared objectives of design groups, and it is within this arena that organizational learning can accommodate and improve the process.

There is a significant library of available literature on the subject of Organisational learning, and techniques for increased efficiency in product design teams. Conversely there is a dearth of literature on the subject of utilizing information technology to assist with the evolution of design teams from one system of thought to another through knowledge acquisition and management. The principle of informating [15] espouses the use of IT as a means of liberating employees by making more information available to all and hence drive learning. A study performed on a company [16] which made defence related products and whose entire business model changed as a result of the collapse of the cold war, employed a computer integrated manufacturing (CIM) strategy to drive a goal of massive cost reduction and improved delivery time. This goal was translated into four key objectives: improved coordination, improved process control, widespread development of automation and finally systems integration. This plan bears a striking resemblance to many models for concurrent engineering and indeed the design teams operated under the appeal of, "Right first time." This can be defined broadly as a drive to reduce the number of design changes and the resulting cost of those changes. In aerospace this should also include the need to identify necessary changes as soon as possible. Process simulation methods, or digital manufacturing techniques, provide a set of tools and resources which simultaneously equip the design engineer with a means of exploring design choices, retaining a record of changes, and outputting instructional materials for the purpose of directing manufacturing staff or training maintenance staff during the product's operational life. The major advantage of process simulation is the ability to investigate design solutions at an early stage of product development previous to any commitment to physical assets. In essence, these digital models provide a means of testing incremental changes to gain rapid feedback on the consequences in order to make continuous adjustments and adaptations, so called "Single loop learning" [17].

Predictive technologies have been developed and integrated into industry as a tool set for design engineers for some time now. However, methods engineers have not been furnished to the same extent with these technologies and there remains a significant communication barrier between the production planners and design practicioners [18]. By extension, engineers concerned with product development from an MRO perspective have not, as yet, been involved at all. There exists a key opportunity to develop and apply predictive tools for the purposes of assisting engineers across all disciplines, providing a digital framework and repository for the entire enterprise and extended supply chain, integrating engineering disciplines and product lifecycle stages and embodying the concept of organisational learning. From the specific view point of availability contracting, these tools also, as a byproduct of digital design and build validation strategies, generate materials which can be used directly for training, thus negating the need for separate instructional authoring for assembly during manufacture and potentially, dis-assembly during maintenance or decomissioning. This is an important factor when considering the issue of knowledge transfer between lifecycle stages as it has been shown that when used for an assembly task, digital 
instructional materials can be a more effective learning tool than traditional hard copy assembly drawings or written instructions [19].

Computer aided design (CAD) and computer aided engineering (CAE) tools now make it possible to manage complex engineering design data in a single integrated environment. In their digital manufacturing role they can inform how a product needs to be built but the same principles are equally applicable to the development of maintenance processes later in the product's lifecycle. The hierarchical structure within the tools facilitates a systematic approach to process management through a Product - Process - Resource (PPR) hub. For manufacturing planning this includes product data in the form of a bill of materials (BOM). This is linked to a process node which defines build order from parts and individual pieces to sub assemblies through to final product assembly. The process data is linked in turn to the resource node which details the production hardware such as tools and fixturing as well as the labour groups required to complete the work. To extend this approach into the availability domain, the process and resource nodes can be extended to include maintenance, repair and overhaul (MRO) activities. In this case product and resource nodes are equivalent to those required for manufacture but the hierarchy within the process node changes from one related solely to the product structure (parts - sub-assemblies -assemblies) to the chronology of the required maintenance program for the platform e.g. the A, B, C, and $\mathrm{D}$ checks required for civil aircraft. Build sequences are then supplemented with processes detailing how the product is dis-assembled and re-built during maintenance. End of life processes can also be defined enabling the management of: high value parts as they are allocated for reuse, the classification and separation of materials as they are extracted for recycling and the identification of waste or hazardous items for disposal. In addition to the procedural aspects of these processes, key business considerations such as cost and important environmental parameters including energy consumption or waste can be hi-lighted as key design drivers.

This work shows how simulation and optimisation strategies for aerospace maintenance provision can be delivered within a learning organisation, using wholly virtual methods and assets. This includes the use of virtual representation of complex engineering problems as a mechanism for enhanced comprehension and communication of concepts across disciplines and enterprises. The utilisation of digital design methodologies to inform component and assembly design for maintenance as the key engineering driver, and how digital techniques can deliver the desired advancement of service provision practices using a systems approach to process design.

\section{Animated work instructions}

At the heart of the animated work instruction research presented here, is the drive to facilitate user responses to complex engineering activities in a more realistic, temporal, and dynamic way. This is a key consideration before any move to availability contracting where OEM and customer assets and resources have to be managed and used collectively making knowledge generation, transfer and management an important element of the successful joint enterprise. Virtual representation of three dimensional components and their motions, with respect to a manufacturing assembly sequence or a maintenance operation, has the obvious advantage over traditional two dimensional formats in that there is no requirement for additional prompts or directives over and above the provision of a drawing, static image or diagram. For example, in two dimensional instructions the fitting of one component with another may require several symbols such as arrows or direct textual instructions to convey the meaning, as well as a formerly developed knowledge base of all tooling to be used, how fasteners are used, and how to operate fixtures 
etc. This in essence requires further interpretation on the part of the operator before carrying out the task. Virtual, or immersive, instructions require only that the operator observes the action and repeats what he/she sees. Past research in the field of animated sequences for learning capability has shown that effectiveness is most pronounced when motion is a critical attribute of the concept being presented and when motion is used to cue or draw the viewer's attention to the material being presented [20]. That said, there is a point at which animation may become ineffective through the violation of the apprehension principle, according to which, graphics should be accurately perceived and appropriately conceived [21]. Where the animations become overly complex or rapid perception is often sacrificed.

From the perspective of the manufacturing sector, the objectives for improved learning capacity include shorter learning curves and reduced error rates leading in turn, to significant cost reductions and delivery lead times. Tang [22] reports an 82\% reduction in error rate, NASA [23] report an $83 \%$ reduction in error rate and $24 \%$ reduction in time to completion, and Lin [24] reports an approximately $45 \%$ reduction in time to completion when virtual training methods are employed. Previous work on this subject involved an independent groups experiment for the purpose of investigating the effects of different instructional media on performance on a small scale mechanical assembly task [25]. Twenty four participants completed the assembly of a reverse rotation device a total of five times. Three types of unimodal instruction sets were designed and delivered via a laptop computer in the form of text only, static CAD diagrams, and dynamic CAD animation. Build times were recorded for each participant and plotted as a learning curve. Results suggested that the use of animated instructions can reduce initial build times, as the mean build time at build one was $37 \%$ than the text only group and $16 \%$ quicker than the diagrams only group. The beneficial effect diminished after the first build, however, the graphics (diagrams and animation) groups continued to yield quicker mean build times up until build 3 .

Central to the use of these digital 3D materials is the construction of an internal conceptual model, or mental model which in the context of a procedural assembly task, will allow for goal formation and a reference point for relating instructional information and for checking progress throughout the build. Although this research was concerned primarily with the generation of instructional materials only, what these outcomes indicate is the potential advantages of utilising a digital environment for the testing of design hypothesis in a format readily understood by all the key parties involved not only in an engineering design group but in the labour groups that execute the processes. This is important when considering

(a)

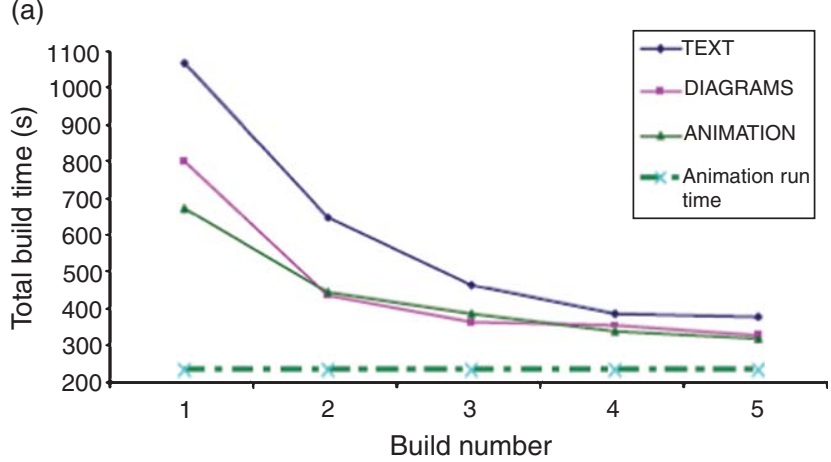

(b)

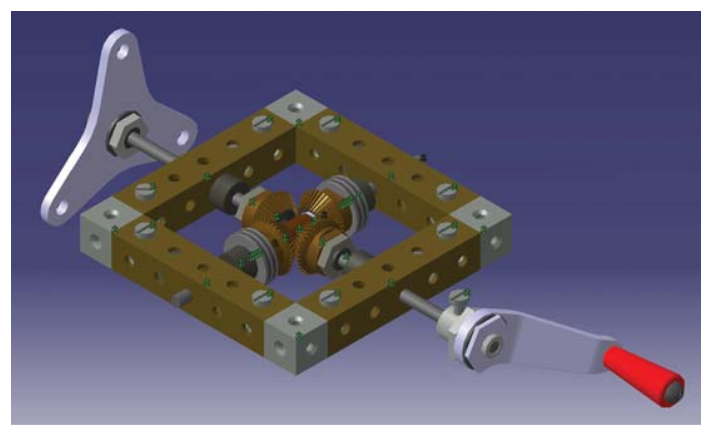

Fig. 1. (a) Mean Build Times for all participants in each of the three instructional groups over the five builds. (b) CAD model of assembled 'Reverse Rotation' device [25]. 
in house labour but becomes critical in an availability contracting context when operators completing maintenance work may be customer or contracted personnel. Lin [24] states that the key objective in using virtual based systems is to develop a, "Knowledge modeling technique to overcome the difficulties arising from complexity of systems and knowledge variety, and to fill the gap between abstract task model and detailed implementation." In this sense the author was referring specifically to training, but the paradigm fits equally well with a broader sense of systems engineering. Li et al [26], in their work on the use of immersive VR on maintenance training state, "At a system level, maintenance engineers need to understand the architecture of the entire system under maintenance while trying to dismantle a specific system component from it. At component level, the engineers need to appreciate the inner structure of the system, such as the spatial relations of system components. With the knowledge acquired, maintenance engineers can then derive the disassembly sequences for maintenance and the implication of each disassembly step [27]. For this purpose, the digital system needs to provide maintenance engineers with means by which they can visualise the entire system under maintenance and its environment." As a clear statement of the intentions of design with maintenance in mind, this would be hard to improve upon.

It is clear from the above that animation can provide a relatively complete mental model for a given process from the outset, resulting in quicker task completion times for production or maintenance operatives, when compared to diagrams or text alone. This advantage may be due to a reduced amount of cognitive reasoning. Extending this finding into the realm of systems engineering suggests that the driving constraints and concerns of maintenance type activity can be accurately modeled and investigated in a wholly virtual environment and in a format readily understood by the largest body of people. This maximises the potential for interaction and learning from all the engineering disciplines concerned throughout any joint enterprise, thereby increasing the likelihood of time and cost compliant process solutions, through improved functional definitions and architectures.

\section{Integrated digital design}

This section describes the development of a methodology that facilitates the integration of design and manufacturing modelling at the concept design stage thereby providing a mechanism for the early provision of process sequences to be delivered in a digital form, which can improve the learning process for the designers. In particular, the methodology allows the user to more readily exploit the digital manufacturing simulation capabilities offered through state-of-the-art software applications [28].

The underlying methodology for integrated digital manufacturing includes the management of product, process and resource (PPR) data, a core theme of most PLM solutions. The optimisation of manufacturing processes in a virtual environment and the integration of that information into the design environment are two potential benefits. A complete digital design and manufacture modeling platform presents an integrating cost framework for all aspects of manufacture (materials, treatments, part fabrication, assembly, quality, tooling, and industrial engineering). Moreover, the DFM linkage can be seamless as design precisely defines the input data then required of the digital manufacturing process. Similarly, downstream life cycle phases such as test and certification, maintenance and operation, and disposal can be integrated into the conceptual design process [29].

A good example of how this could be achieved is the evolution of the design stages that were developed for the generation of a fuselage panel design that is optimised for direct operating cost (DOC) at a configuration level. The concept can then be investigated for manufacturability, to include assembly, 


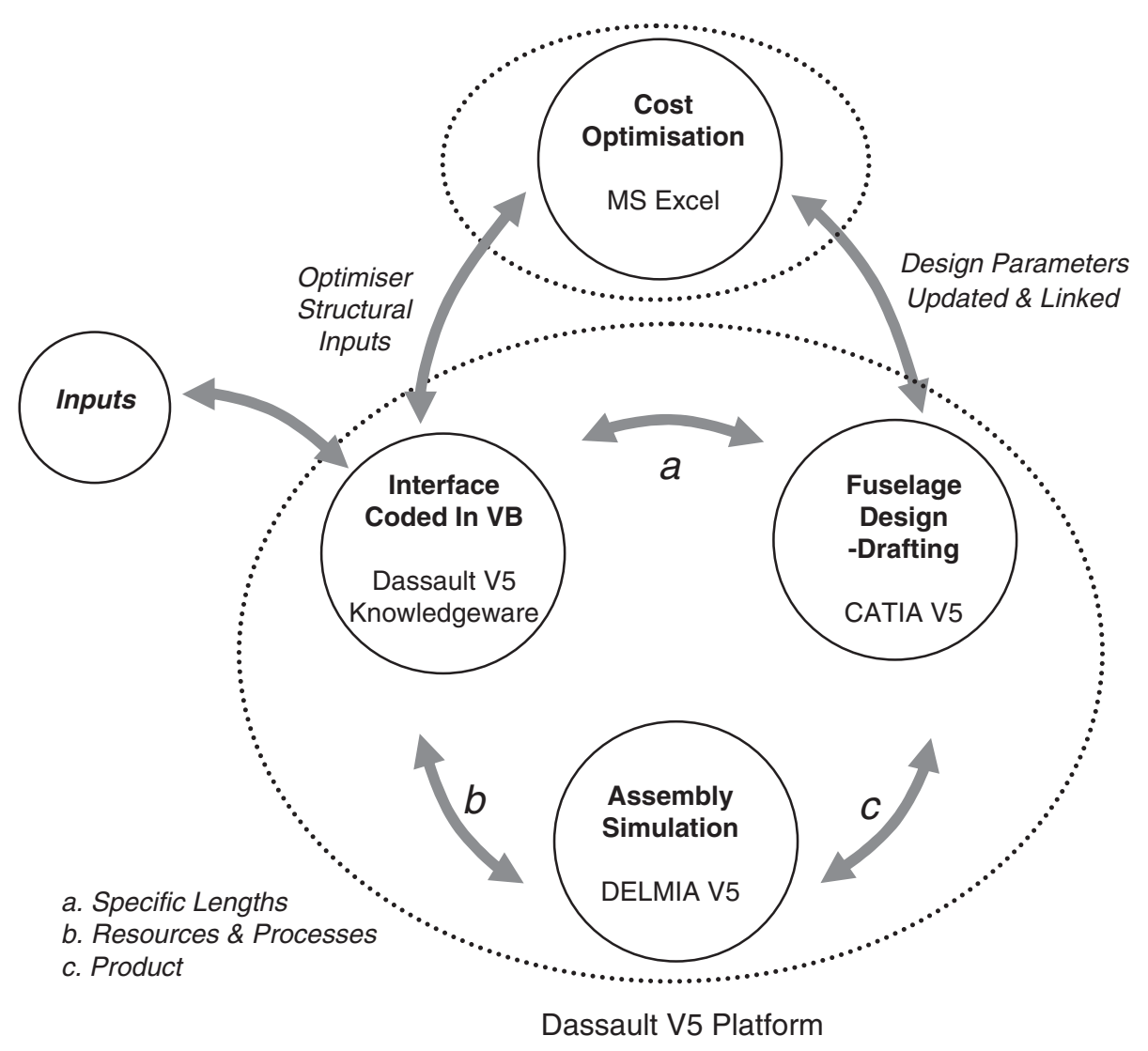

Fig. 2. Optimisation Flow diagram.

planning and the provision for all relevant data necessary for subsequent stages in production. The first stage uses a spreadsheet to generate the geometric definition of the panel, see Fig. 2. A spreadsheet analysis tool driven by a range of structural failure limitations and design constraints, computes an optimised structural design. This is then used as the basis for the automatic generation of a 3D CAD model, which couples the spreadsheet analysis to the design parameters and variables. When complete this results in a full product definition that is suitable for direct input to the digital manufacturing simulation platforms for the purpose of assembly process design. Delmia process engineer (DPE) is used to generate the manufacturing bill of materials (M-BOM) from the consolidated engineering bill of materials (E-BOM) produced by the design stages described above. The M-BOM is then used to define the production stages and the associated resource utilisation for the detailed manufacturing optimisation. The methodology that drives this approach is concurrent with regard to being able to consider both design and manufacturing factors at the one point in time very early in the process. In general, it has been shown that a knowledge based engineering (KBE) approach can be encoded as a methodology for exploiting 3-D design modeling and manufacturing simulation capabilities. In addition, this can be driven by the integration of cost into the development tool in order to generate cost-effective solutions, in terms of both MFCs and DOC, relative to the fuel burn penalty associated with structural weight. The methodology is flexible and can be easily extended in terms of complexity or the application. For example, relative to the work presented, the DPE database can easily be developed in a modular fashion in order to cover a wide 
range of associated structures and processes that are linked through the visual basic (VB) interface (to facilitate wing panel design using friction stir welding of various stringer sections for example), or more specifically to the broader subject being treated here, to a maintenance driven component or assembly design. The main contribution of this work is to present a methodology that facilitates the integration of design and manufacturing modeling at the conceptual design stage, and in particular allows the user to more readily exploit the digital manufacturing simulation capabilities offered through state-of-the-art software applications to actively encourage concurrent engineering principles. This methodology again utilises available technologies and techniques to converge organizational learning with the key objectives of an engineering development environment.

\section{Digitally modeled component replacement}

The concept of applying digital methods directly to learning in a maintenance driven process design application has been demonstrated using the replacement of a significant airframe panel within the front end of an attack aircraft (see Fig. 3). Although normal maintenance procedures had been established for this aircraft, the replacement of the panel in question had not been anticipated within the expected operational lifetime of the platform and there were no design allowances or documented procedures in existence for its removel and replacement. Previous attempts to develop a methodology using manual methods on a real aircraft, proved to be costly and time consuming and the technical challenge was complicated further by restricted access.

The airframe components, associated fixtures and spatial constraints around the exemplar panel, were modeled utilising the Product Process and Resource (PPR) structure within Dassault Systemes' Delmia digital manufacturing resulting in a detailed work breakdown structure. This 'hub' can be used to service all of the key digital functionalities used for engineering process design such as the build validation techniques available in DPM (Digital Process for Manufacture) which was also used for this work. Simulations were used to develop and validate specific procedural options using animations with clash detection functions, as well as ergonomic analysis. In essence, the digital tools utilised here, allow the designer to test engineering decisions using criteria fundamental to part removal and replacement, and thus generate an optimal solution to identify and quantify, the costs associated with this type of maintenance activity. From a learning perspective, the ability of the design engineer to attempt design features which may not have been familiar to them previously, to test those concepts and accept or reject those proposals dependant on the result, and to collaborate with maintenance experts through a universal visual medium, is a powerful tool in the arsenal of learning.

Figure 3 Illustrates the three main stages required for panel replacement. Each of these static images represents a single frame from a fully animated process definition which included detailed representations of each task required to complete the work. Each of the processes shown in Fig. 3, was broken down into sub-activities with different requirements in tooling, labour and hence time and cost. Many of the sub tasks and activities were derived directly from the simulation as optimised solutions were developed.

Referring to Fig. 4. The inter-relationship between the different design drivers and the CAD model can be seen. Here, each of the satellite functions is used to test individual design solutions according to the criteria derived form - process definition, clash detection, assembly validation and human analysis. The assembly model drives the position of each component. Clash detection determines the ability of any component, tool or operator to move through the work space to its final position without fouling on surrounding items. Human analysis assesses the ability of the operator to maneuver and locate components 


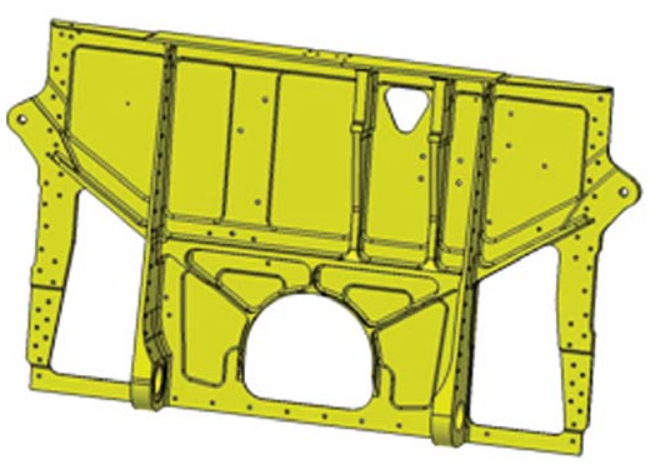

(a)

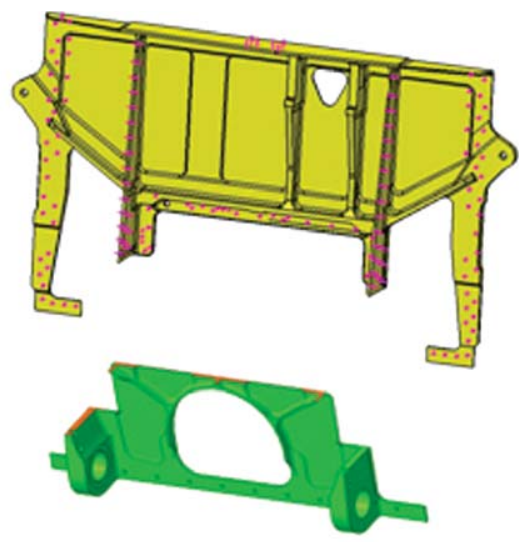

(b)

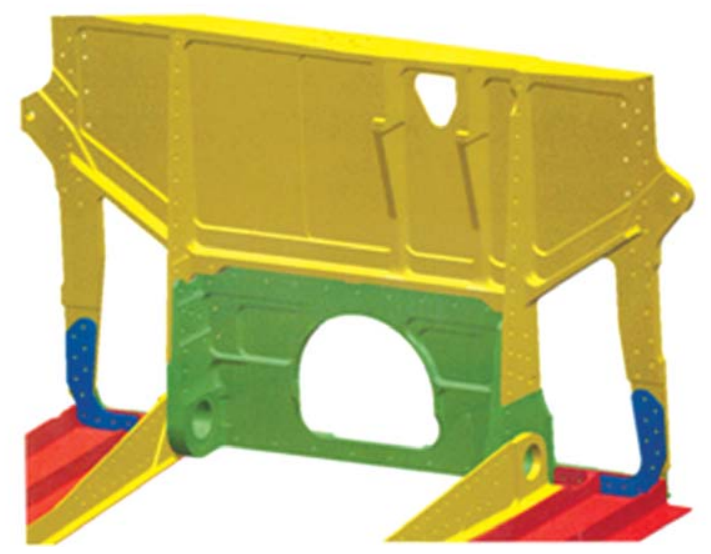

(c)

Fig. 3. Pintle frame replacement. (a) Original. (b) Redundant material removed. (c) Replacement complete.

or tools in a comfortable and accurate manner. The process definition satellite (DPE) determines the work breakdown structure and hence the order of component and tool entry to the final assembly by determining the optimum order of tasks. Should any one test reveal an impractical or impossible outcome to the proposed solution, an informed decision can be made to alter the geometry of components, fixtures, tool choice or the work breakdown structure. The altered proposal can be tested again if necessary and the optimal solution reached. Here we see a further opportunity for the involvement of experts, other than the design engineer, to enter the process and affect the outcome, and all within the same digital environment. CAD representation of tooling items, such as the hand held miniature milling machine, were added to the assembly model to ascertain if there was sufficient clearance between them and the surrounding airframe structure as the panel replacement work was carried out (see Fig. 5). Clash detection was utilised as a means of providing immediate feedback as to the practicability of the tool's position at all points along its path of motion.

Human analysis was used to establish the comfort with which the mill could be handled as it was guided along the cutting path (see Fig. 6). In this case the analysis of posture indicates a severe limiting 


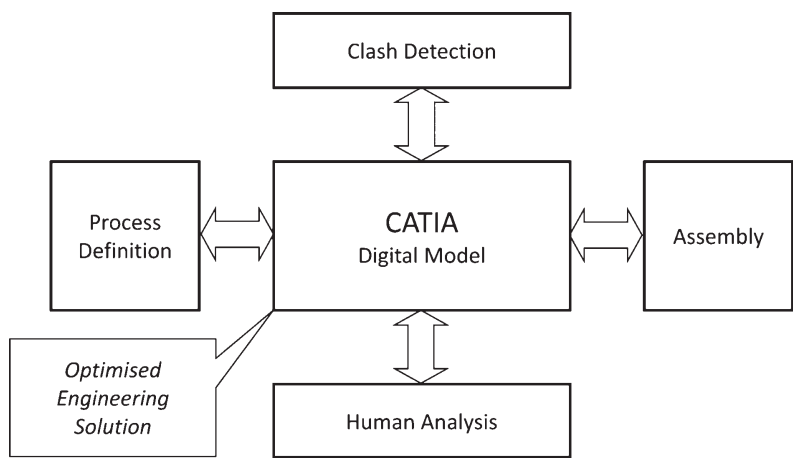

Fig. 4. Illustration of iterative nature of model development.

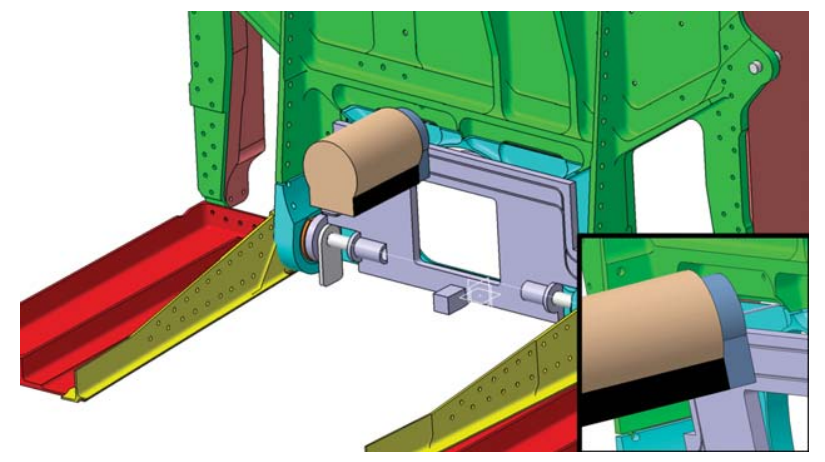

Fig. 5. Simulation of milling tool progressing around cutting path.

on lateral and transverse application of force available to the operator, and hence a clear design choice to focus on longitudinal handling to execute the task. In response, the associated tooling designed to meet this particular objective was designed with longitudinal handling as the key ergonomic requirement.

This data informed the final choice of power tool from a list of available options which were shortlisted according to primary performance criteria. These included spindle speed, power source, cutting tool capacity, torque and overall dimensions. The driving factors from the clash detection and human analysis led to the final choice of a miniature milling machine.

A fully animated representation of the panel replacement activity was generated for the purpose of defining the work breakdown structure. Here the process order and the specific details of each process are shown as virtual movement of the components and the tooling, as is intended to occur in the real world scenario. Supplimentory written instructions accompany these animations and they appear as dialogue boxes at the points most appropriate to the specific processes. These instructions contain the details that are not immediately apparent from the animation e.g. specific tool or fastener codes. Using this approach for optimal process development negated the need for separate work instruction authoring. This example is based on the retrofit of a component on a pre-existing aircraft, however, if we imagine such components being designed at the primary stage of a new product, with the intention of removal at some stage of the life cycle as part of an MRO activity, it can be seen clearly that the animated instructions outputted directly from the design process could be passed out to MRO staff at the operator's installations. 


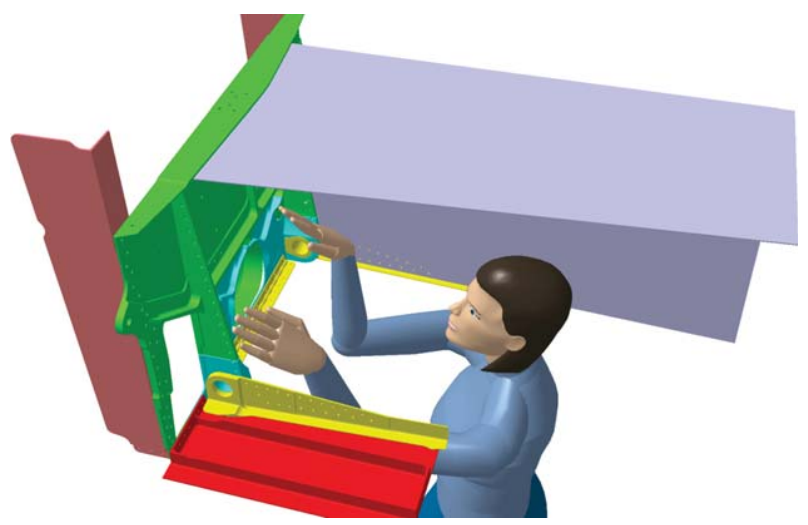

Fig. 6. Human analysis simulation in context of work environment.

\section{Discussion}

This work shows how simulation and the principles of digital manufacturing can be extended into the design of MRO activities on a complex aerospace platform. This in turn, supports the transition of an OEM to availability based contracting as a learning organization.

The functionality of the tools within the simulation framework which have previously been utilised only to in a manufacturing context, allows complete system definition through the generation of virtual engineering issues, thus creating a universal medium for the distribution and shared comprehension of design activities. The concept is predicated on the use of a universally accessible medium for the communication of complex engineering issues which may, ordinarily, be beyond the understanding of those individuals outside the specialty. In this way all parties involved within the product development organisation can be invested with a shared sense of understanding and consequent influence upon the design process. The work reported here shows a clear improvement in the accuracy of mental model development through this medium and a clear suggestion that this method is a practical and effective means of knowledge generation and transfer. Further to this, engineers at the component design level have an opportunity to develop and test disassembly sequences for maintenance activities and explore the necessary implications of each step. It follows that a closer optimisation of design choices can be approached.

Given the aforementioned advantages of the virtual development of design methods, it follows that extending the capabilities of such visual media to include the physical qualities of the components and assemblies would avail a powerful model for improved design processes. Clash detection, assembly models, human analysis and digital process definition and related data retention are all possible within the environment reported here. Real world issues relating to maintenance can be embedded within the virtual model and drive the design choices made by the engineer, including the hierarchical summation of sub system process definitions and parameters within a PPR structure. The simulations deliver process details from an engineering perspective, which include work breakdown structures for maintenance operations, delivery of representative times for machining and manual activities, identification of cost drivers such as labour, tooling, fixturing, inventory etc., and the generation of instructional materials [19]. More importantly, the enhanced PPR structure demonstrated here, provides an integrated framework for the generation, management and delivery of engineering process definitions. Within a single enterprise, this facilitates concurrent activities between the engineering disciplines and promotes the 'heads up' 
approach required for the application of systems thinking to lifecycle design for aerospace applications. The transparent, collaborative environment has been enhanced to include maintenance activities, as the process node in the manufacturing hub is extended to include the broader product lifecycle.

The integrated digital framework presented here also facilitates the integration of the design, manufacturing and maintenance disciplines within a single collaborative environment and as a result encourages learning activity. As platform complexity resulted in disciplinary divergence in aircraft design in the past, this technology promotes their convergence through the configuration of the PPR structure to manage a broad range of inputs ranging from product design through manufacturing planning to maintenance process definition. The development of manufacturing processes through virtual assets and the integration of that information into the design environment is easily altered to include maintenance processes. A complete digital product modeling platform presents an integrated framework for all aspects of design, allowing downstream life cycle phases such as test and certification, maintenance and operation, and disposal to be integrated into the conceptual design process.

\section{Conclusions}

Previous research has shown how simulation can support a system lifecycle approach to manufacturing process development and maintenance planning in aerospace. The methods used here show how a digital environment can deliver tangible outcomes in terms of shared objectives in a design team through organisational learning. The evolution of manufacturing simulation techniques for use in maintenance process design has been demonstrated. Methodologies for the planning of maintenance activities as part of the overall product design have been identified, demonstrating that maintenance activities can be supported using digital tools. Specific outputs which accurately inform design decisions as well as contracting specification can be directly extracted from the digital simulations.

\section{Acknowledgments}

The funding provided by the Engineering and Physical Sciences Research Council (EPSRC) to complete this work is gratefully acknowledged. We would also to thank BAE Systems. Without their technical guidance and support this work would not have been possible.

\section{References}

[1] Report by the comptroller and auditor general. Ministry of Defence: Through Life Management, 19th May 2003.

[2] Y. Ward and A. Graves, Through life management: A catalyst for process excellence in customer support and maintenance, repair \& overhaul (MRO). UK lean aerospace initiative report, May 2006.

[3] J. Womack and D. Jones, Lean consumption, Harvard business review 83(3) (March 2005), 58-68.

[4] H. Mathe and R. Shapiro, Integrating Service Strategy in the Manufacturing Company, Chapman and Hall, London, 1993.

[5] V. Mathieu, Service strategies within the manufacturing sector: Benefits, costs and partnership, International Journal of Service Industry Management 12(5) (2001), 451-475.

[6] R. Oliva and R. Kallenberg, Managing the transition from products to services, International Journal of Service Industry Management 14(2) (2003), 160-172.

[7] V. McConnell, Composites in the sky with dreamliner, Aviation maintenance, May 2005.

[8] J. Persinos, What composites mean for you, Aviation maintenance, June 2009.

[9] C.J. Hockley, Design for success, Proceedings of the Institute of Mechanical Engineers 212 (Part G), 371-378. 
[10] L. Webb and C. Bil, Knowledge management for the through life support of aircraft, Proceedings of SimTecT, Melbourne, May 2008.

[11] G. Probst and B. Büchel, Organisational learning: The competitive advantage of the future, Prentice Hall 1997, ISBN: 0-13-462326-6.

[12] K. Eisenhardt and B.N. Tabrizi, Accelerating adaptive processes: Product innovation in the global computer industry, Administrative science quarterly 40, 1995, pp. 84-110.

[13] K. Ayas, Project design for learning and innovation: Lessons learned from action research in an aircraft manufacturing company, SAGE Publications, 1999, pp. 177-193.

[14] M. Hoegl and H.G. Gemuenden, Teamwork quality and success of innovative projects: A theoretical concept and empirical evidence, Organization science 12(4) (Aug 2001), 435-449.

[15] S. Zuboff, In the age of the smart machine: The future of work and power, Oxford Heinemann, 1988.

[16] F. Blackler, et al., Organizational learning and organizational forgetting: Lessons from a high technology company, SAGE Publications, 1999, pp. 194-216.

[17] C. Argyris, Single loop and double loop models in research on decision making, Administrative science quarterly 21 (3) (Sep 1976), 363-375.

[18] J. Butterfield, I. Ng, R. Roy and W. McEwan, Enabling value co-production in the provision of support service engineering solutions using digital manufacturing methods, Proceedings of Winter Simulation Conference, Hilton Austin Hotel, 13th-16th December 2009.

[19] J. Butterfield, R. Curran, G. Watson, C. Craig, S. Raghunathan, R. Collins, T. Edgar, C. Higgins, R. Burke, P. Kelly and C. Gibson, Use of digital manufacturing to improve operator learning in aerospace assembly. Paper Number: AIAA 2007-7865. 7th AIAA Aviation Technology, Integration and Operations Conference (ATIO), 2nd Centre of Excellence for Integrated Aircraft Technologies (CEIAT) International Conference on Innovation and Integration in Aerospace Sciences. Hastings Europa Hotel, Belfast, Northern Ireland, 18-20 September 2007.

[20] Anglin, et al., Visual representations and learning: The role of static and animated graphics, In: D.H. Jonassen, Handbook of Research on Educational Communications and Technology, 2nd ed., Lawrence Erlbaum Associates, Mahwah, NJ, 2004, pp. 865-916.

[21] Tversky, et al., Animation: Can it facilitate? International Journal of Human-Computer Studies 57 (2002), $247-262$.

[22] A. Tang, et al., Comparative Effectiveness of Augmented Reality in Object Assembly, New techniques for presenting instructions and transcripts, In: CHI, 2003, Ft Lauderdale, Florida.

[23] A. Tang, et al., Experimental evaluation of augmented reality in object assembly task, Proceedings of the International Symposium on Mixed and Augmented Reality (ISMAR'02).

[24] F. Lin, et al, Developing virtual environments for industrial training, Information sciences 140 (2002), 153-170.

[25] Watson, et al., The effect of using animated work instructions over text and static graphics when performing a small scale engineering assembly, Proceedings of the 15th ISPE International Conference on Concurrent Engineering, 2008.

[26] J. Li, et al., Desktop virtual reality for maintenance training: An object oriented prototype system (V-REALISM), Computers in Industry 52 (2003), 109-125.

[27] J. Butterfield and W. McEwan, A System Lifecycle Approach to Maintenance Planning in Aerospace Using Digital Manufacturing, AIAA.

[28] R. Curran, et al., Integrated digital design for manufacture for reduced life cycle cost, International Journal of Production Economics 109 (2007), 27-40.

[29] A.R. Mileham et al., A parametric approach to cost estimating at the conceptual stage of design, Journal of Engineering Design 4(2) 1993, pp. 117-125. 